\title{
Level I fieldwork today: A study of contexts and perceptions.
}

\author{
Caryn Johnson \\ Thomas Jefferson University \\ Kristie P. Koenig \\ Temple University \\ Catherine Verrier Piersol \\ Philadelphia University \\ Susan E. Santalucia \\ University of the Sciences in Philadelphia, Philadelphia, \\ Wendy Wachter-Schutz \\ Harcum College \\ Follow this and additional works at: https://jdc.jefferson.edu/otfp \\ Part of the Occupational Therapy Commons \\ Let us know how access to this document benefits you
}

\section{Recommended Citation}

Johnson, Caryn; Koenig, Kristie P.; Piersol, Catherine Verrier; Santalucia, Susan E.; and WachterSchutz, Wendy, "Level I fieldwork today: A study of contexts and perceptions." (2006).

Department of Occupational Therapy Faculty Papers. Paper 41.

https://jdc.jefferson.edu/otfp/41

This Article is brought to you for free and open access by the Jefferson Digital Commons. The Jefferson Digital Commons is a service of Thomas Jefferson University's Center for Teaching and Learning (CTL). The Commons is a showcase for Jefferson books and journals, peer-reviewed scholarly publications, unique historical collections from the University archives, and teaching tools. The Jefferson Digital Commons allows researchers and interested readers anywhere in the world to learn about and keep up to date with Jefferson scholarship. This article has been accepted for inclusion in Department of Occupational Therapy Faculty Papers by an authorized administrator of the Jefferson Digital Commons. For more information, please contact: JeffersonDigitalCommons@jefferson.edu. 


\section{Level I Fieldwork Today: \\ A Study of Contexts and Perceptions}

\author{
Caryn R. Johnson, \\ Kristie P. Koenig, \\ Catherine Verrier Piersol, \\ Susan E. Santalucia, \\ Wendy Wachter-Schutz
}

Caryn R. Johnson, MS, OTR/L, FAOTA, is Academic Fieldwork Coordinator, Thomas Jefferson University, Jefferson College of Health Professions, Department of Occupational Therapy, 130 South 9th Street, Philadelphia, Pennsylvania 19107.

Kristie P. Koenig, PhD, OTR/L, is Assistant Professor, Temple University, Philadelphia, Pennsylvania.

Catherine Verrier Piersol, MS, OTR/L, is Associate Professor and Program Director, Occupational Therapy Program, Philadelphia University, Philadelphia, Pennsylvania. She was Academic Fieldwork Coordinator at the time of this study.

Susan E. Santalucia, MS, OTR/L, was Academic Fieldwork Coordinator, University of the Sciences in Philadelphia, Philadelphia, Pennsylvania, at the time of this study.

Wendy Wachter-Schutz, OTR/L, was Academic Fieldwork Coordinator, Harcum College, Bryn Mawr, Pennsylvania, at the time of this study.
The last comprehensive examination of the Level I fieldwork experience was performed 15 years ago (Shalik, 1990) and addressed the different types of settings in which fieldwork occurred; amounts and types of supervision; structure and scheduling of the Level I experiences; and the effects of supervising Level I students on productivity. Although every occupational therapy and occupational therapy assistant student encounters a number of Level I fieldwork opportunities, little is available describing the process and contexts of the Level I fieldwork experience today. This study, which examines 1,002 student reports on Level I fieldwork experiences, finds that Level I fieldwork today occurs in a wide variety of physical disability, pediatric, mental health, and emerging practice settings. Findings also indicate that, whereas most fieldwork educators are occupational therapy practitioners, more fieldwork educators are non-occupational therapists than in the past. Furthermore, although students reported opportunities to practice observation and communication across all settings, practice of other clinical skills was specific to type of settings, and opportunities to practice were limited. Student perceptions about opportunities for experiencing occupation-based practice, observation of theory in practice, and how students value different types of fieldwork experiences are addressed. In addition, this study explores the expansion of Level I fieldwork into emerging practice arenas and how students perceive those experiences.

Johnson, C. R., Koenig, K. P., Piersol, C. V., Santalucia, S. E., \& Wachter-Schutz, W. (2006). Level I fieldwork today: A study of contexts and perceptions. American Journal of Occupational Therapy, 60, 275-287.

\section{Introduction}

Level I fieldwork is an integral part of every occupational therapy student's experience, mandated by the Accreditation Council for Occupational Therapy Education $\left(\right.$ ACOTE $^{\circledR}$ ) (American Occupational Therapy Association [AOTA], 1999). The purpose of Level I fieldwork "is to introduce students to the fieldwork experience, and develop a basic comfort level with and understanding of the needs of clients" (p. 581) while providing students with opportunities to observe and participate in the occupational therapy process (AOTA, 1999). These broad guidelines allow for great flexibility in the design of Level I fieldwork, resulting in wide variation from program to program regarding the types of sites, timing and scheduling of the fieldwork experience, course objectives, and types of supervision (Kautzman, 1987; Leonardelli \& Caruso, 1986; Shalik, 1990).

As evidenced year after year in self-reflection assignments and classroom discussion, students attach great value to their Level I fieldwork experiences, which often reaffirm their choice of occupational therapy as a career and may influence future career decisions and directions. A positive experience-in which the student actively participates, observes best practice, and is exposed to good role models and provided with opportunities to apply classroom learning-will move the student along the path to becoming a competent practitioner. Experiences lacking these elements may leave the student ill-prepared for the demands of Level II fieldwork and practice. The Level I experience also plays an important role in evaluating and promoting the development of professional behaviors that are crucial to successful performance as an occupational therapy practitioner (Koenig, Johnson, Morano, \& Ducette, 2003).

Despite the obvious benefits of this wide range of options to fulfill a critical aspect of occupational therapy education, surprisingly little descriptive or systematic 
research has been conducted regarding the fieldwork experiences. This lack of information generates important questions about what is actually being experienced by students in Level I fieldwork today and how these experiences have changed over time.

Some of the aspects of practice that have changed over time include the physical and conceptual contexts. In order to appropriately prepare students for current practice, the fieldwork components of the curriculum should reflect this. Today's students have the opportunity to experience occupational therapy practice in settings ranging from homeless shelters to neonatal intensive care units, with fieldwork educators ranging from community workers to occupational therapists. Questions the authors chose to address in order to examine the characteristics of today's fieldwork settings include the following:

- In what contexts, or settings, is Level I fieldwork occurring? Are these settings reflective of where today's occupational therapists are practicing?

- Does Level I fieldwork today reflect changes in practice, such as the movement by practitioners into emerging practice settings?

- What types of qualifications do today's fieldwork educators have?

Comparing fieldwork today to fieldwork of the past will enable us to identify trends, explore current issues, and prepare for the future.

Student experiences with and perceptions of Level I fieldwork are likely to vary as widely as the range of students themselves. These perceptions are valuable to each educational program and may be used for purposes of evaluating the current fieldwork program and guiding future development in areas such as course objectives, preparation of fieldwork educators, and selection of fieldwork settings. Many factors contribute to the way the student perceives his or her experience, such as comfort level with the supervisory experience; comfort with or interest in a particular setting or population; and whether the student has opportunities to actively participate or is limited to observation. And although occupation-based practice is taught as the gold standard in academic settings, students often report that they do not see such practice reflected in the clinical setting, creating a dissonance between what they are learning in the classroom and what they are seeing in practice. Questions the authors chose to address regarding student perceptions include the following:

- Are students being provided with opportunities for active participation where they can practice clinical skills in preparation for Level II fieldwork and practice?

- How are students experiencing occupation-based practice? Theory in practice?
- How do the type of setting and qualifications of the fieldwork educator influence students' perceptions of Level I fieldwork?

This study-a snapshot of the Level I fieldwork experience at the beginning of a new millennium-addresses the need to better understand the process and contexts of Level I fieldwork. It is designed to describe important qualities of the contemporary fieldwork experience, including types of settings where Level I fieldwork occurs, qualifications of Level I fieldwork educators, and student perceptions of the Level I fieldwork experience in traditional and emerging practice settings. Greater understanding of the Level I fieldwork experience has the potential to enable academic programs to better prepare students for successful Level II experiences and transition into practice, and better prepare fieldwork sites and educators to train students in accordance with professional standards. This increased awareness may also help educators and practitioners reflect on the dissonance between what students are taught in school and actually see in practice. Finally, a fuller understanding of fieldwork may be useful in guiding future development of educational policies and academic standards and identifying future areas of research.

\section{Literature Review}

\section{Fieldwork Contexts: Supervision and Settings}

Level I fieldwork was first referenced in the 1973 Essentials and Guidelines of an Accredited Educational Program for the Occupational Therapist (often referred to as the Essentials) (AOTA, 1975). The purpose of Level I fieldwork was to provide students with "initial and basic experiences in directed observation and participation in selected field settings" (AOTA, 1975, p. 486). Supervision was to be provided by "qualified competent personnel, who may or may not be occupational therapy personnel" (AOTA, 1975, p. 486).

Over the last 30 years, very little has changed in the requirements for Level I fieldwork. The 1983 and 1991 Essentials and the 1998 Standards for an Accredited Educational Program for the Occupational Therapist (often referred to as the Standards) all concur that Level I fieldwork is required and its purpose is to enrich the student's learning experience through observation and participation in the occupational therapy process (AOTA, 1983, 1991, 1995, 1999). Fieldwork educators may include, but need not be limited to, "psychologists, physician assistants, teachers, social workers, nurses, and physical therapists" (AOTA, 1999, p. 581). Being an occupational therapist has never been a requirement for Level I fieldwork educators. The latitude provided by this guideline has allowed students 
exposure to a wide range of service providers and settings, as well as access to Level I fieldwork educators even when occupational therapy practitioners have been in short supply.

The vast majority of Level I fieldwork educators have been occupational therapists. In a nationwide Level I fieldwork study that addressed types of settings, scheduling, supervision, and the effects on productivity, Shalik (1990) found that in $95 \%$ of the 395 responses, the fieldwork educators were occupational therapists. In addition, students tend to prefer fieldwork educators who were occupational therapists over non-occupational therapy fieldwork educators (Heine \& Bennett, 2003). Recent articles describing Level I fieldwork in emerging practice settings may be indicative of the increasing use of non-occupational therapy fieldwork educators (LaGrossa, 2005; Moffett Boyd \& Garbarini, 2001; Scott, 2000).

Guidelines pertaining to fieldwork settings have changed somewhat over the past 40 years. The 1998 Standards require that Level II fieldwork expose the student to a "variety of clients across the lifespan and to a variety of settings," but specify only that Level I fieldwork should "enrich didactic coursework through directed observation and participation in selected aspects of the occupational therapy process" (AOTA, 1999, p. 581). For many years, the Essentials for occupational therapy programs required Level II fieldwork in physical dysfunction and psychosocial settings (AOTA, 1983, 1991, 1998; Council on Medical Education of the American Medical Association \& AOTA, 1965); however, no such stipulations were made for Level I fieldwork. Some information can be gleaned from previous fieldwork studies. Shalik's 1990 study revealed that in the late 1980 s, $43 \%$ of Level I placements occurred in physical dysfunction settings, $55 \%$ of which were located in hospitals. Twenty percent occurred in psychosocial settings, 75\% of which were in hospitals. Pediatric settings accounted for $19 \%$ (more than $55 \%$ of these were located in schools), and $10 \%$ occurred in other settings, including nursing homes, geriatric settings, and developmental disability settings, most of which were residential (Shalik, 1990). Academic programs reported that they required Level I fieldwork in specified areas. Eighty-eight percent of educational programs required Level I fieldwork in psychosocial settings, $85 \%$ in physical dysfunction settings, $65 \%$ in pediatric settings, $28 \%$ in geriatric settings, and $14 \%$ in other settings (Shalik, 1990).

In a 1986 study, Leonardelli and Caruso examined cost-effectiveness, supervisor time commitment for Level I fieldwork education, desirability of a uniform Level I evaluation tool, and issues related to training Level I fieldwork students from multiple programs. They also addressed the questions of who should develop the fieldwork objectives, design the learning experience, and evaluate the students. Their survey was distributed nationally to academic programs and fieldwork sites. A majority of the 66 respondents agreed that the academic program should be responsible for determining fieldwork objectives, that fieldwork educators should be responsible for designing the learning experiences and evaluating student performance, and that a universal evaluation tool would be useful. Cost-effectiveness was a concern among a majority of fieldwork educators, and preferences for student scheduling patterns varied widely. In a second survey, 47 of 99 respondents reported working in acute care facilities, 9 in long-term-care facilities, and the remainder in rehabilitation facilities or settings that were both acute and long-term-care (Leonardelli \& Caruso, 1986). It was not stated which of these were physical dysfunction, mental health, or pediatric facilities, and neither study referred to emerging practice settings.

\section{Movement Into Emerging Practice Settings}

Level I fieldwork experiences in emerging practice settings were first described in the occupational therapy literature in the mid-1970s (Cromwell \& Kielhofner, 1976; Platt, Martell, \& Clements, 1977). However, the impetus for more rapid expansion into nontraditional arenas did not occur until nearly 20 years later. In the 1990s, a need for alternative fieldwork strategies was identified because there was a shortage of Level I fieldwork sites (Cohn \& Christ, 1995; Crist, 1991). Responses to this crisis included alternative supervision models, such as group supervision (Crist, 1991; 1993; Yanoshak, Fuguet, \& Rose, 1997) and development of fieldwork opportunities in emerging practice environments where students could be supervised by non-occupational therapy personnel or occupational therapy faculty preceptors (Barnes, 1995; Drake, 1992; Hubbard, 2000; Moffett Boyd \& Garbarini, 2001; Moffett Boyd \& Garbarini, 2004; Rydeen, Kautzmann, Cowan, \& Benzing, 1995; Scott, 2000).

Changes in the direction of health care also contributed to the interest and development of occupational therapy services in emerging settings (Cohn \& Crist, 1995), and the 1998 Standards, for the first time, specified emerging practice settings as a Level II fieldwork option and provided guidance regarding supervision and scheduling (AOTA, 1999). Leaders in fieldwork education called on academic programs and fieldwork educators to "provide practical [fieldwork] experiences addressing emerging issues such as quality of life, client self-determination, advocacy, health promotion, [and] disease prevention" in order to prepare students for the movement of health care services into the community (Cohn \& Crist, 1995, p. 104). 
Some academic programs partnered with community agencies to create innovative community-based fieldwork opportunities in settings such as day-care centers, Head Start programs, and halfway houses (Rydeen et al., 1995). This trend has continued, and is currently exemplified in the Scholarship of Practice program at the University of Illinois at Chicago, Duquesne University's Practice-Scholar Program, and Thomas Jefferson University's New Doors Model (Gourley, 2001; Kielhofner, 2002; LaGrossa, 2005). These programs identify needs in the local community where occupational therapy services have not been traditionally provided, then form partnerships among the academic program, occupational therapy practitioners, community agencies, or fieldwork students to provide occupational therapy services to underserved populations. An occasional added benefit is the creation of new occupational therapy positions in emerging practice settings (Kielhofner, 2002; LaGrossa, 2005). Although articles about innovative Level II experiences in settings such as shelters, transitional housing, and adult foster-care homes appear regularly in the occupational therapy periodicals (Follis \& Nolen, 2001; Kerr, 1999; McCreedy, 1994), a systematic examination of Level I fieldwork in emerging practice arenas has not previously been undertaken.

\section{Student Perceptions of Fieldwork}

Most of the literature addresses how students, sites, and universities benefit from participating in fieldwork experiences, with little to indicate how the students perceive or value the experience. In novel settings such as remote rural schools, day-care settings, psychiatric day programs, summer camps, and wellness centers, students developed cultural sensitivity (Moffett Boyd \& Garbarini, 2001) and had opportunities to practice evaluation and treatment, problem solving, management, leadership, collaboration with team members, clinical reasoning, group process skills, and consultation and program development skills (Moffett Boyd \& Garbarini, 2004; Scott, 2000). As fieldwork in these emerging practice environments becomes increasingly common, it is important to examine the process of fieldwork in these settings and how students perceive and value these experiences.

One earlier study examined perceptions of Level I fieldwork by students, faculty members, and fieldwork educators (Kautzmann, 1987). Respondents to a questionnaire were asked to rank their 10 most valued choices from a list of 24 fieldwork objectives based on 4 categories: student involvement in the treatment process, students' understanding of the program and facility, role of the occupational therapist, and students' growth as emerging health professionals. All three groups ranked objectives related to student involvement in the treatment process most highly, although there were significant differences between groups on how they valued individual items within that category. Student responses indicated that they "want and expect hands-on experience, not just observation" (Kautzmann, 1987, p. 599). The sample size was small and limited to the state of Wisconsin.

Leonardelli and Caruso (1986) examined differences between how fieldwork settings and academic programs ranked a variety of Level I fieldwork objectives. Whereas academic programs ranked "hands-on" experience fourth out of 14, fieldwork educators ranked it sixth. Shalik (1990) indicated that most Level I students were passive observers rather than active participants and that students had less opportunity for active participation in physical disability and pediatric settings than in psychosocial and other settings. In contrast, more recent literature indicates that active participation is valued, expected, and encouraged. Heine and Bennett (2003) found that both occupational therapy and non-occupational therapy fieldwork educators encouraged active participation. In addition, Level I student evaluation forms often include a section concerning how the student implements treatment, or actively participates, under the supervision of an occupational therapy practitioner.

Little in the literature spoke to students' experiences with observing theory in practice or experiences with occupation-based practice. The ACOTE Standards (AOTA, 1999) and the new AOTA Fieldwork Performance Evaluations (AOTA, 2002) both emphasize the use of occupation-based practice, yet students continue to report observations of patients stacking cones and placing pegs in holes. Ranking of fieldwork objectives in terms of importance indicated that academic faculty members and students ranked exposure to application of theory third of the top 10 objectives, whereas fieldwork educators ranked it as first out of 10 (Kautzmann, 1987). Although Kautzmann did not specifically identify participation in occupationbased practice as a fieldwork objective, she included items such as introduction to evaluation and treatment techniques, treatment philosophy of the facility, and patterns of practice in occupational therapy, all of which may be related to occupation-based treatment. Treatment philosophy of the facility and patterns of practice in occupational therapy did not rank among the top 10; however, introduction to evaluation and treatment techniques ranked second in importance to students, fourth for fieldwork educators, and eighth for academic faculty members. More recent literature reveals student concerns about the use of activities they believed were meaningless to clients (Heine \& Bennett, 2003), and reflects that there may be discrepancies between 
how students are prepared academically and what they experience in fieldwork regarding occupation-based and evidence-based treatment (Baum, 2000).

Although several older studies yielded information about fieldwork settings, supervision, and student perceptions, very little systematic study of Level I fieldwork exists in the recent literature, necessitating further study. The purpose of this study was to identify types of settings where Level I fieldwork is occurring today, the qualifications of individuals supervising Level I students, and student perceptions of Level I fieldwork in terms of the value of the experience and opportunities to participate in occupationbased practice, observe theory in practice, and practice clinical skills.

\section{Method}

\section{Design}

This research used a retrospective analysis to describe the settings and student experiences of Level I fieldwork for four occupational therapy programs and one occupational therapy assistant program. Data for the study were gathered from a questionnaire adopted by the five schools participating in the study. During the 30-month study period from 1999 to 2002, a total of 1,002 evaluations of fieldwork experiences were collected. Multiple evaluations were collected from 498 occupational therapy students and 49 occupational therapy assistant students. The hour requirements for each Level I fieldwork experience ranged from a low of 48 hours ( 1 day/week for 6 weeks) to a high of 80 hours (10 consecutive days), depending on the academic program, with the average Level I fieldwork consisting of 64 required hours. Specific fieldwork objectives varied from program to program, but all contained an emphasis on active participation and practicing clinical skills. Analysis consisted of descriptive statistics for demographic data and analyses of variance to compare students' perceptions of fieldwork experiences.

\section{Sample}

The sample of convenience included 547 students (23 males and 524 females; $M=23.8$ years, $S D=3.87$ ) enrolled in four entry-level occupational therapy programs and one occupational therapy assistant program in a metropolitan area in the northeast United States. Students were assigned to Level I fieldwork sites by their respective academic fieldwork coordinators (AFCs). On completion of each Level I fieldwork experience, students completed the questionnaire and reviewed it with their supervisors on the last day of fieldwork. The completion of the questionnaire had no impact on grade, but students were required to turn it in to the AFC, resulting in a $100 \%$ response rate. Each student was assigned an identification number. Because the student evaluation of the fieldwork experience was already an existing part of each school's course evaluation, informed consent was not required.

\section{Procedures/Instrument}

The instrument for this study, Student Evaluation of Level I Fieldwork, or SELF (see Figure 1), was developed by the AFCs from the five participating schools, for the purpose of collecting data about Level I fieldwork experiences from the students. The AFCs had an average of 6 years' experience in fieldwork coordination, giving them a high level of expertise. Existing instruments used by each participating school to evaluate the Level I fieldwork experience were reviewed by the AFCs and relevant content was included in the new instrument. The items on the instrument were reviewed for content validity, and demographic information was expanded to include qualifications of the supervisor, position in the sequence of the fieldwork experiences, opportunity to practice clinical skills, and type of practice setting. Specific psychometric tests have not been completed on the SELF.

The SELF consists of four sections: (a) supervision, (b) application of knowledge, (c) facility, and (d) clinical skills. All but one section (clinical skills) was scored using a 5point Likert scale $(1=$ strongly disagree to $5=$ strongly agree). The clinical skills section is designed to identify the clinical skills that students had an opportunity to actually practice and was coded as a dichotomous variable. A site code was assigned to each experience to categorize the types of settings students were experiencing.

\section{Data Management and Analysis}

Data and demographic information from the SELF were entered into a database using the Statistical Package for the Social Sciences (SPSS), version 12.0. All data were entered by research assistants who visually inspected the data and analyzed the data for errors. All data were entered with the exception of one question regarding the students' perceived value of assignments, because of the program specificity of those items.

To analyze the setting data in a meaningful way and to assess group differences, the initial 21 site codes were collapsed to reflect the three traditional areas of practice (physical disabilities, mental health, and pediatrics) and a fourth category labeled "emerging practice." The five AFCs independently reviewed all sites that were used during the time period of the study and then reached $100 \%$ consensus on classification of the sites. A site was coded as an emerging 


\section{Philadelphia Region Fieldwork Consortium Student Evaluation of Level I Fieldwork}

Student name

Supervisor name (print)

Site name:

Site ID code: Student Age:

Course number: Student ID code : Student Gender: [ M ] [ F ]

Semester:

Year:

School:

Degree:

Sequence:

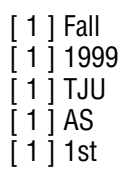

3 ] Summer

[ 3 ] 2001

[ 2 ] Spring
[ 2 ] 2000
$[2$ ] TU
$[2$ ] BS
$[2$ ] 2nd

[ 3 ] MS

[ 3 ] 3rd

$3=$ Neutral $\begin{array}{lllll}1 & 2 & 3 & 4 & 5 \\ 1 & 2 & 3 & 4 & 5 \\ 1 & 2 & 3 & 4 & 5 \\ 1 & 2 & 3 & 4 & 5 \\ 1 & 2 & 3 & 4 & 5 \\ 1 & 2 & 3 & 4 & 5 \\ 1 & 2 & 3 & 4 & 5 \\ 1 & 2 & 3 & 4 & 5 \\ 1 & 2 & 3 & 4 & 5 \\ 1 & 2 & 3 & 4 & 5\end{array}$

$\begin{array}{lllll}1 & 2 & 3 & 4 & 5\end{array}$

$\begin{array}{lllll}1 & 2 & 3 & 4 & 5\end{array}$

$\begin{array}{lllll}1 & 2 & 3 & 4 & 5\end{array}$

$\begin{array}{lllll}1 & 2 & 3 & 4 & 5\end{array}$

$\begin{array}{lllll}1 & 2 & 3 & 4 & 5\end{array}$

15. There were opportunities for "hands-on" involvement

\section{ASSIGNMENTS:}

Indicate the value of written assignments.

$1=$ Worthless 2 = Minimal value 3 = Valuable $4=$ Very valuable 5 = Exceptional

16.

17.

18.

19.

COMMENTS:

\section{FACILITY}

1 = Strongly Disagree $\quad 2$ = Disagree $\quad 3=$ Neutral $\quad 4=$ Agree $\quad 5=$ Strongly agree

20. The environment was conducive to learning

21. There were adequate opportunities to interface with patients/clients

22. There were adequate interdisciplinary opportunities

23. This was a valuable experience

24. Should there be any additions to or deletions from the FWI program? $1=$ yes $2=$ no Comments:

25. Do you feel the role of $\mathrm{OT}$ is (or could be) important to the total treatment program of the patient/client in this facility? $1=$ yes $2=$ no COMMENTS:

CLINICAL SKILLS: Which clinical skills did you have an opportunity to practice (circle all that apply)?
26. A/PROM exercises
34. HR/BP/respirations
27. ADLs
35. interviewing
28. chart review
29. communication skills
36. MMT
30. documentation
31. feeding
32. fine/gross motor activities
37. Observation
38. leading groups
39. Sensory integration
48. splinting
50. transfers/mobility techniques
42. Wellness principles
43. Therapeutic use of self
44. Behavior management
45. Patient/family education
33. Goniometry
46. Other assessments:
47. Other interventions:
49. Other:

COMMENTS:

\section{GENERAL COMMENTS:}

Student signature Date

Supervisor signature Date

\section{Figure 1.}


practice setting if it met the following criteria: (a) no occupational therapist on site, (b) no Level II fieldwork students on site providing supervision, (c) potential existed for clients to benefit from occupational therapy services, and (d) potential existed for students to engage in program development or service learning. The addition of "emerging practice" in this study is reflective of the changes occurring in occupational therapy practice today (Moffet Boyd \& Garbarini, 2001), as more occupational therapists enter this arena of practice.

Analysis of variance (ANOVA) was used to compare the dependent variables of students' perceptions (including perceptions of supervision, opportunities to apply knowledge, and the learning environment within the facility) across the independent variables of setting (physical disabilities, mental health, pediatrics, and emerging practice) and the supervisor's professional background (occupational therapist, occupational therapy assistant, Level II occupational therapy student, and non-occupational therapist). A series of one-way ANOVAs was performed to assess group differences. A two-way (fieldwork educator x setting) analysis was not possible because of several empty cell means (i.e., no non-occupational therapy personnel supervised in a pediatric setting). Because of multiple comparisons, a Bonferroni correction procedure was also used to protect against Type I error with the corrected $p$ value reduced to .005 . These analytic tasks allowed the investigators to describe and compare differences in the students' perceptions across the supervisor's professional background and setting.

\section{Results}

This study first examined the characteristics of today's fieldwork settings. Level I fieldwork continues to occur across a wide variety of settings. Table 1 identifies the types of settings where Level I fieldwork is occurring, including the traditional practice settings of physical disabilities, mental health and pediatrics, as well as emerging practice. As can be seen in Table 1, there is considerable variety and student participation in emerging practice settings.
Information was also obtained on the qualifications of the fieldwork educators. In this regional sample, occupational therapists supervised $82.6 \%$ of student experiences; professionals from other disciplines (nurses, social workers, community workers) were responsible for $11.6 \%$ of the supervision; Level II fieldwork students supervised $3.3 \%$; and occupational therapy assistants supervised $2.5 \%$ of student experiences. One mental health site in the regional area relies exclusively on Level II fieldwork students to supervise all of their Level I students, which accounts for all of the students in the study supervised by Level II students.

The second aspect of the study addressed student perceptions of the fieldwork experience. Summaries of data on clinical skills that Level I students had the opportunity to practice is presented in Table 2.

Comparison by setting indicates that observation and communication skills are the most commonly practiced skills across settings. Clinical skills that are practiced with a high level of frequency, but appear to be unique to practice setting, include: range of motion $(82 \%)$ in physical disabilities; behavior management $(73 \%)$ in mental health; fine and gross motor activities (94\%) in pediatrics; and interviewing $(77 \%)$ in emerging practice settings. Other skills typically required by practitioners in specific settings were practiced at a lower level of frequency. For example, only $41 \%$ of students in physical disability settings had an opportunity to practice goniometry. Of those students completing fieldwork in pediatric settings, only $27 \%$ had an opportunity to practice feeding.

To analyze how type of setting and fieldwork educator affect the students' perceptions of their Level I fieldwork experience, a series of one-way ANOVAs with a pairwise comparison of means using Tukey's honestly significant difference (HSD) was conducted to assess differences in perception in the two content areas of application of knowledge and facility. It should be noted that the variables under study were negatively skewed significantly, indicating that most respondents scored the items in the higher range of scores, restricting the range of scores. A

Table 1. Setting Types for Level I Fieldwork Experience $(N=1,002)$

\begin{tabular}{|c|c|c|c|c|c|c|c|}
\hline \multicolumn{2}{|c|}{ Physical Disabilities $(n=415)$} & \multicolumn{2}{|c|}{ Mental Health $(n=158)$} & \multicolumn{2}{|c|}{ Pediatrics $(n=232)$} & \multicolumn{2}{|c|}{ Emerging Practice $(n=197)$} \\
\hline General & $34 \%$ & Hospital & $43 \%$ & Community & $44 \%$ & Senior Centers & $34 \%$ \\
\hline Rehabilitation & $22 \%$ & Community & $30 \%$ & Schools & $39 \%$ & Assisted Living & $20 \%$ \\
\hline Outpatient & $19 \%$ & $\mathrm{MH} / \mathrm{MR} / \mathrm{DD}$ & $27 \%$ & Hospital & $17 \%$ & Sheltered Workshops & $18 \%$ \\
\hline Home Health & $8 \%$ & & & & & Homeless Shelter & $16 \%$ \\
\hline Nursing Home & $8 \%$ & & & & & After-School Programs & $10 \%$ \\
\hline Hand Center & $6 \%$ & & & & & International & $2 \%$ \\
\hline Other* & $3 \%$ & & & & & & \\
\hline
\end{tabular}

*Settings in the "Other" category included specialty sites exclusive to Traumatic Brain Injury, Spinal Cord Injury, and Assistive Technology.

Note. All programs were coded independently by each program and then checked for accuracy so that all sites that were used were coded in the same manner. $\mathrm{MH} / \mathrm{MR} / \mathrm{DD}=$ mental health/mental retardation/developmental disabilities. 
Table 2. Percentage of Clinical Skills Practiced in Level I Fieldwork Settings

\begin{tabular}{|c|c|c|c|c|}
\hline Skill & $\begin{array}{c}\text { Pediatric } \\
\text { settings } \\
(n=232)\end{array}$ & $\begin{array}{c}\text { Physical } \\
\text { Disabilities } \\
(n=158)\end{array}$ & $\begin{array}{c}\text { Mental } \\
\text { Health } \\
(n=232)\end{array}$ & $\begin{array}{c}\text { Emerging } \\
\text { Practice } \\
(n=197)\end{array}$ \\
\hline Observation & 97 & 99 & 98 & 94 \\
\hline Communication & 94 & 95 & 98 & 96 \\
\hline Charting & 83 & 90 & 79 & 90 \\
\hline Documentation & 72 & 80 & 63 & 38 \\
\hline ROM & 48 & 82 & 15 & 24 \\
\hline Goniometry & 10 & 41 & 8 & 2 \\
\hline MMT & 14 & 53 & 5 & 7 \\
\hline ADLs & 47 & 72 & 40 & 34 \\
\hline Transfers & 7 & 66 & 17 & 24 \\
\hline Education & 43 & 52 & 44 & 46 \\
\hline Interviewing & 45 & 74 & 63 & 77 \\
\hline Use of Self & 84 & 75 & 83 & 81 \\
\hline Gross/Fine Motor & 94 & 77 & 68 & 65 \\
\hline $\mathrm{HR} / \mathrm{BP}$ & 6 & 51 & 3 & 8 \\
\hline Wellness & 23 & 47 & 59 & 52 \\
\hline Splinting & 16 & 37 & 6 & 4 \\
\hline Groups & 35 & 27 & 72 & 76 \\
\hline Feeding & 27 & 24 & 22 & 24 \\
\hline Behavior Management & 64 & 19 & 73 & 47 \\
\hline Sensory Integration & 69 & 16 & 27 & 18 \\
\hline
\end{tabular}

Note. $\mathrm{ROM}$ = range of motion; MMT = manual muscle test; $\mathrm{ADLS}=$ activities of daily living; $\mathrm{HR} / \mathrm{BP}=$ heart rate/blood pressure.

power transformation using squaring to reduce the negative skew was applied to the data, which resulted in a more normal distribution.

Students' perceptions of the opportunities they had to apply their knowledge, engage in occupation-based practice, and observe theory in practice were influenced by both setting and type of fieldwork educator. In the application of knowledge items, a series of one-way ANOVAs indicated a significant effect for fieldwork educator and significant effect for setting. Specifically, the type of fieldwork educator had a significant effect on the students' observations of theory in practice, $F(3,998)=31.89, p<.001$; participation in occupation-based practice, $F(3,998)=11.54, p<.001$; and opportunity for hands-on involvement, $F(3,998)=$ 7.04, $p<.001$. Post hoc testing indicated that students supervised by non-occupational therapy personnel $(M=$ 3.31) observed significantly less theory in practice when compared to those supervised by Level II fieldwork students $(M=4.09)$, occupational therapists $(M=4.13)$, and occupational therapy assistants $(M=4.20)$. Students supervised by non-occupational therapy personnel $(M=3.80)$ also perceived significantly less opportunity to engage in occupation-based practice than students supervised by Level II fieldwork students $(M=4.21)$ and occupational therapists $(M=4.27)$. Students supervised by occupational therapy assistants $(M=4.04)$ and non-occupational therapy personnel $(M=4.26)$ perceived significantly less opportunity to practice clinical skills than those supervised by occupational therapists $(M=4.53)$. Setting also had a significant effect on opportunities to apply knowledge on Level I fieldwork. Setting had a significant effect on students' observations of theory in practice, $F(3,998)=29.14, p<.001$; participation in occupation-based practice, $F(3,998)=8.91, p$ $<.001$; and opportunity to practice clinical skills, $F(3,998)$ $=6.12, p<.001$. Post hoc testing indicated that students in emerging practice settings $(M=3.53)$ observed significantly less theory in practice when compared to those in mental health $(M=4.08)$, physical disabilities $(M=4.14)$, and pediatric settings $(M=4.22)$. Students in emerging practice areas $(M=4.01)$ also perceived significantly less opportunity to engage in occupation-based practice than students in mental health $(M=4.25)$ and pediatric settings $(M=4.41)$. In addition, students in physical disability settings $(M=$ 4.17) perceived significantly less opportunity to engage in occupation-based practice than students in pediatric settings $(M=4.41)$. Students in emerging practice $(M=4.39)$ and physical disability settings $(M=4.41)$ perceived significantly less opportunity to practice clinical skills than students in pediatric $(M=4.61)$ and mental health settings $(M=4.63)$.

Items related to the learning environment within the facility, specifically students' perceptions of the value of the experience, were affected by fieldwork educator and setting. Specifically, the type of fieldwork educator had a significant effect $F(3,998)=9.68, p<.001$ on students' perceptions of the value of the experience, as did the type of setting $F(3$, $998)=9.83, p<.001$. A Tukey HSD test showed that students supervised by occupational therapists $(M=4.74)$ or occupational therapy assistants $(M=4.88)$ indicated that their Level I fieldwork was a significantly more valuable experience than students supervised by Level II fieldwork students $(M=4.48)$ or non-occupational therapy personnel $(M=4.49)$. In addition, students who were in physical disability $(M=4.76)$ or pediatric settings $(M=4.81)$ indicated a significantly more valuable experience than those in emerging practice settings $(M=4.56)$ or mental health $(M$ $=4.61)$ settings. It is important to note that in general all students perceived their Level I fieldwork experiences as valuable, as indicated by the mean scores.

\section{Discussion}

\section{Level I Fieldwork Settings}

The results of this study reveal that Level I fieldwork is being conducted in all four types of settings: mental health, physical disabilities, pediatrics, and emerging practice, with the majority of experiences occurring in physical disability settings. The literature supports that this trend has been consistent at least since the late 1980s (Shalik, 1990). These 
results are also consistent with the latest AOTA Member Compensation Survey, which indicates that the greatest number of occupational therapists are practicing in physical disability settings, followed by those practicing in school or early intervention settings (AOTA, 2001). The most recent practice analysis by the National Board for Certification in Occupational Therapy (NBCOT) also supports this distribution among entry-level occupational therapists (NBCOT, 2004). In contrast, the percentage of students completing fieldwork in emerging practice settings far exceeds the percentage of occupational therapists reporting practicing in community settings. This discrepancy may be a result of differences in how these practice arenas were defined for each of these studies, or it may suggest that educational programs have identified unmet needs for occupational therapy services and are preparing students for future practice in areas in which occupational therapy services are not yet established.

\section{Fieldwork Educator Qualifications}

Findings that occupational therapists provide the majority of supervision to occupational therapy and occupational therapy assistant students are consistent with the 1990 Shalik study. Surprisingly, in the current study, occupational therapy assistants provided supervision in only $2.5 \%$ of the experiences, whereas occupational therapy assistant students comprise $4.9 \%$ of the experiences. This was less than the supervision provided by Level II fieldwork students, and may be because of lack of willingness, opportunity, or administrative support. The results are somewhat alarming, given that occupational therapy students and occupational therapy assistant students can benefit from the wealth of knowledge and experience that occupational therapy assistants, who in Pennsylvania comprise approximately $36 \%$ of active NBCOT certificants (NBCOT, 2003), can provide. Questions arise as to why occupational therapy assistants are so minimally involved with Level I fieldwork education, and perhaps why they are so underused in general. Whereas further investigation is warranted to understand this nominal involvement of occupational therapy assistants, the new Educational Standards, which emphasize collaboration between occupational therapists and occupational therapy assistants (AOTA, 1999), may help to facilitate future involvement by occupational therapy assistants in fieldwork education and other professional activities.

\section{Emerging Practice}

Corresponding with the emergence of nontraditional practice settings for occupational therapists and occupational therapy assistants, the literature and the results of this study reveal that students are completing Level I fieldwork experiences in emerging practice arenas (Cohn \& Crist, 1995). The frequency of supervision by non-occupational therapy personnel has more than doubled in the past 20 years, from $5 \%$ in the late 1980 s (Shalik, 1990) to $11.6 \%$ today, reflecting the increase of Level I fieldwork experience in emerging practice settings. Recognition of Level II fieldwork in emerging practice arenas by ACOTE in the 1998 Standards is likely to support continued growth of fieldwork opportunities in these areas (AOTA, 1999).

Interviewing was reported to be the most frequently practiced clinical skill in emerging practice settings, with students reporting opportunities to practice this skill $77 \%$ of the time. Given the nature of emerging practice settings, in which established evaluation and intervention tools are not always available or appropriate, students are encouraged to use the interview format in order to familiarize themselves with the site and the service recipients. In addition, students are challenged to articulate the benefits of occupational therapy in the practice setting (Moffett Boyd \& Garbarini, 2001).

It is worth noting that whereas nearly $20 \%$ of all Level I placements took place in emerging practice settings, only about $3 \%$ to $4 \%$ of occupational therapists and occupational therapy assistants report working in community/ other settings (AOTA, 2001). This finding suggests that whereas academic programs are introducing students to the growing but still limited area of emerging practice, we are simultaneously stimulating interest in emerging practice arenas so that our graduates will be empowered to create the jobs of the future.

\section{Practice Opportunities and Student Perceptions}

The results of our study indicate that students were provided with opportunities to practice clinical skills in all types of settings. Students reported that they were most commonly able to practice observation and communication skills across all types of settings. In physical disabilities, mental health, and pediatric settings, students reported practicing skills reflective of the specific type of setting. For example, in physical disability settings, range of motion was reported to be the most frequently practiced clinical skill, as was expected. However, students reported practicing manual muscle testing, heart rate and blood pressure measurement, goniometry, and splinting in 53\% or less of their physical disabilities experiences. Similarly, students in pediatric settings reported practicing transfers, splinting, feeding, and activities of daily living in less than $50 \%$ of their experiences.

Based on these results, it appears that even though the Standards require participation-and students, academic 
programs, and fieldwork educators value and encourage it - students may not be getting the opportunities to practice the clinical skills necessary to begin to develop skill and confidence in these areas with "real" client populations during Level I fieldwork. Because fieldwork is designed to progress students through higher levels of skill and responsibility (AOTA, 2003), it follows that students who have opportunities to practice clinical skills and experience occupation-based practice in the Level I fieldwork experiences will be better prepared to practice occupation-based therapy in their Level II fieldwork experiences. This limited opportunity to practice clinical skills may explain why students may be perceived as unprepared in Level II fieldwork settings where they are often expected to "hit the ground running." It is important for fieldwork educators who plan clinical skills orientation and training for Level II fieldwork students to realize that Level I fieldwork frequently does not offer the student the opportunity to practice and gain confidence in certain clinical skills.

Regarding students' perceptions of the value of their fieldwork experiences, the results indicate that differences existed based on fieldwork educator qualifications. Generally, students rated their Level I fieldwork experiences as valuable. Fieldwork experiences were rated more valuable when students were supervised by occupational therapists and occupational therapy assistants, as compared to Level II fieldwork students and non-occupational therapy personnel. These findings would seem to indicate that students prefer being supervised by "real occupational therapists." The high rankings in general, however, indicate that students were still able to appreciate the value of these experiences.

Reportedly, the type of fieldwork educator had a considerable effect on the student's observation of theory in practice, participation in occupation-based practice, and opportunity for practicing clinical skills. Experiences in which non-occupational therapy personnel in emerging practice sites supervised students indicated less observation of theory, less opportunity to engage in occupation-based practice, and less opportunity to practice clinical skills. The lower frequency of observation of occupation-based practice was unexpected, given that occupational therapy theories and the essence of "occupation" are inherent to emerging practice arenas. Since non-occupational therapy personnel do not necessarily use occupational therapy terminology or have the skills to identify theoretical concepts, it becomes incumbent on academic educators and fieldwork coordinators to assume responsibility for mentoring, preparing, and educating students for these experiences, enabling them to recognize occupation-based practice in non-traditional environments. Students also perceived less opportunity to practice clinical skills when supervised by occupational therapy assistants. This finding also warrants further investigation.

Student perceptions of fieldwork experiences indicate that there were differences based on type of setting. The results indicate that the use of theory was observed more in mental health, physical disabilities, and pediatrics compared to emerging practice. More participation in occupation-based practice and clinical skills was reported in mental health and pediatrics compared to physical disabilities and emerging practice settings. Given that the largest percentage of fieldwork experiences (41.4\%) occurred in physical disability settings, this is of concern. More valuable experiences were reported in physical disability and pediatric settings compared to mental health and emerging practice settings. This perception may be reflective of the students' anticipated area of practice. New graduates are more likely to practice in pediatric and physical disability settings than in mental health and emerging practice settings (NBCOT, 2004). Students may value a fieldwork experience more highly when they plan on practicing in that type of setting. Until more occupational therapists and occupational therapy assistants begin working in community settings and become available to train fieldwork students, supervisors will continue to be drawn from other pools of professionals. Although this supervision model may not be the students' first choice in all situations, it nonetheless provides them with opportunities for promoting occupational therapy to other professionals, consumers, and the public; appreciating the role of the occupational therapist as an entrepreneur; and developing the ability to advocate for consumers and assist them in gaining access to occupational therapy services_-all areas academic curricula are required to address (AOTA, 1999).

\section{Study Limitations}

Although the number of fieldwork experiences was large $(N=1,002)$, the study results are limited to one small area of the country; therefore, the results may not generalize to other geographic regions. The restricted range of scores (most students indicated a high degree of satisfaction with Level I fieldwork) may have positively skewed the data in that the students' overall sense of satisfaction with the Level I fieldwork experience may have influenced their scoring in other areas. Therefore, results should be interpreted cautiously.

No validity or reliability testing was performed on the evaluation tool before implementation, which would have further supported the results. In addition, although all programs in the study emphasized observation and participation in the Level I fieldwork experience, course-related 
Level I fieldwork learning objectives were not standardized between academic programs, which may have influenced how students interpreted and rated each item on the survey.

Lastly, this study did not address temporal issues, including when the fieldwork experience occurred within the curriculum or the effect the length of the fieldwork experience may have had on opportunities to practice clinical skills.

\section{Conclusion}

Little has changed in Level I fieldwork requirements since 1973, but the characteristics of Level I fieldwork have changed. Level I fieldwork experiences continue to include physical disabilities, mental health (to a much lesser degree than previously), and pediatric settings (to a much greater degree than previously), with the majority of Level I fieldwork experiences occurring in physical disability settings. Emerging practice settings comprise a more significant portion of these experiences now than in the past, reflecting the current trend of occupational therapy expansion into nontraditional areas and its integration into occupational therapy curricula. The majority of students are supervised by occupational therapists, as opposed to occupational therapy assistants, Level II fieldwork students, or non-occupational therapy personnel.

Overall, this study found that students value Level I fieldwork independent of variables such as setting, type of supervisor, and degree of active participation in clinical skills. However, the findings indicated that students valued the experience more highly when provided with opportunities to practice clinical skills, to observe theory in practice, and to participate in occupation-based practice. Based on the results and discussion, several implications emerge for academic educators and fieldwork coordinators as well as clinical fieldwork educators.

Academic educators and fieldwork coordinators need to continue to teach and promote occupation-based practice to students and clinical fieldwork educators. Physical disability settings, although the most frequently reported experience, were rated lowest by students in terms of opportunities to participate in occupation-based practice. Educating and providing examples for occupation-based practice in physical disability settings should be emphasized. Academic programs can promote occupation-based practice by providing in-services to supervising therapists, designing Level I fieldwork assignments that focus on occupation-based intervention, and empowering students to discuss and seek opportunities to participate in occupationbased practice during their Level I fieldwork experiences. For example, Level I fieldwork students can be encouraged to formally interview clients to gain insight into the person's illness experience, as well as their interests and routines. Using that information, the student could design an occupation-based intervention activity for the client. Fieldwork educators could be encouraged to provide opportunities to discuss their clinical reasoning process with students- to share the process they go through to create occupationbased activities within the context of their setting.

Academic fieldwork coordinators need to educate clinical fieldwork educators about the purpose of the Level I fieldwork experience, encouraging and supporting opportunities for hands-on involvement. Fieldwork educator training workshops provided by academic programs both regionally and nationally can highlight the needs identified by this research and include content on how fieldwork educators can facilitate active participation across settings. It is incumbent on the Level II fieldwork educator to assess, not assume, the student's competence and provide education and training as indicated.

Of concern is the minimal number of occupational therapy assistants in the role of fieldwork educator. Occupational therapy assistants are an integral part of service delivery and should be encouraged and trained to supervise Level I fieldwork students. Academic fieldwork coordinators and fieldwork educators must collaborate to facilitate the involvement of more occupational therapy assistants in fieldwork education. Marketing that targets occupational therapy assistants regarding the importance and benefits of supervising fieldwork students-including documentation of continued competence and exposure through students to new and emerging concepts in occupational therapy-could promote participation of occupational therapy assistants in fieldwork supervision.

Lastly, students are successfully participating in Level I fieldwork experiences in a variety of emerging practice settings. The finding that students reported less participation in occupation-based practice in emerging practice settings was unexpected, since the emerging practice setting is often the clients' natural environment where they typically engage in work, leisure, and self-care occupations. Although it is important for AFCs to continue placing students in supportive emerging practice settings and developing relationships with non-occupational therapy practitioners, additional education and mentoring may be beneficial in order to foster students' understanding of the relationship between occupational therapy theory and the inherent use of occupation in these settings.

Non-occupational therapy personnel who provide fieldwork education may also require formal education as to the nature of occupational therapy practice. Greater awareness can be achieved through fieldwork site visits or by 
inviting willing participants to the academic setting. By educating non-occupational therapy fieldwork educators, faculty members and AFCs can not only facilitate a positive experience for their students, but can also increase the public's awareness of occupational therapy.

This study has implications for future research. Given the geographic limitation of this study, replication in other parts of the country would be of interest. This study also found that students reported limited opportunities to practice clinical skills during Level I fieldwork experiences. The impact this may have on their performance in Level II fieldwork could be investigated. In addition, the fieldwork educator's perceptions of Level I fieldwork would provide valuable comparative information. Future research could also examine structural differences (i.e., amount of time, course objectives, placement by fieldwork coordinator versus selfplacement) in Level I fieldwork and their impact on student experiences.

\section{Acknowledgments}

The authors would like to thank the hundreds of fieldwork educators and students from Thomas Jefferson University, Temple University, Philadelphia University, University of the Sciences in Philadelphia, and Harcum College who contributed to the collection of this data and make the job of being a fieldwork coordinator such a wondrous one.

\section{References}

American Occupational Therapy Association (1975). Essentials of an accredited educational program for the occupational therapist. American Journal of Occupational Therapy, 29, 485-496.

American Occupational Therapy Association (1983). Essentials of an accredited educational program for the occupational therapist. American Journal of Occupational Therapy, 37, 817-823.

American Occupational Therapy Association (1991). Essentials and guidelines for an accredited educational program for the occupational therapist. American Journal of Occupational Therapy, 45, 1077-1084.

American Occupational Therapy Association (1995). Updated 1991 essentials and guidelines for an accredited educational program for the occupational therapist (7/95). In AOTA Accreditation Council for Occupational Therapy Education: Accreditation Manual (pp. 1-12). AOTA: Bethesda, MD.

American Occupational Therapy Association (1999). Standards for an accredited educational program for the occupational therapist. American Journal of Occupational Therapy, 53, 575-582.

American Occupational Therapy Association (2001). AOTA 2000 member compensation survey. Bethesda, MD: Author.
American Occupational Therapy Association (2002). Fieldwork performance evaluation for the occupational therapy assistant and the occupational therapy student. Bethesda, MD: Author.

American Occupational Therapy Association (2003). The purpose and value of occupational therapy fieldwork education. American Journal of Occupational Therapy, 57, 644.

Barnes, M. A. (1995, December). Putting it all together: Occupational therapy in community contexts. Education Special Interest Section Newsletter 2(4), 3-5.

Baum, C. (2000, January 3). Reinventing ourselves for the new millennium. OT Practice, 12-15.

Cohn, E. S., \& Crist, P. (1995). Back to the future: New approaches to fieldwork education. American Journal of Occupational Therapy, 49, 103-106.

Council on Medical Education of the American Medical Association and the American Occupational Therapy Association (1965). Essentials of an accredited curriculum in occupational therapy. New York, NY: American Occupational Therapy Association.

Crist, P. A. (1991, December). Fieldwork education: Possible solutions to current dilemmas. Education Special Interest Section Newsletter, 1(1), 3, 6.

Crist, P. A. (1993, March). Nontraditional and group fieldwork models: Their time has come. Education Special Interest Section Newsletter, 3(1), 3-4

Cromwell, F. S., \& Kielhofner, G. W. (1976). An educational strategy for occupational therapy community service. American Journal of Occupational Therapy, 30, 629-633.

Drake, M. (1992). Level I fieldwork in a day care for homeless children. Occupational Therapy in Health Care, 8, 215-224.

Follis, D., \& Nolen, A. (2001, May 7). Our journey into the community. OT Practice, 12-16.

Gourley, M. (2001, December 17). Innovative academiccommunity partnerships. OT Practice, 6-7.

Heine, D., \& Bennett, N. (2003). Student perceptions of Level I fieldwork supervision. Occupational Therapy in Health Care, 17, 89-97.

Hubbard, S. (2000, December 18). A case example of remote supervision. OT Practice, 16-18.

Kautzmann, L. N. (1987). Perceptions of the purpose of Level I fieldwork. American Journal of Occupational Therapy, 40, 595-600.

Kerr, T. (1999, March 8). Do-it-yourself fieldwork inspired Michigan students. Advance for Occupational Therapy Practitioners, 30, 33.

Kielhofner, G. (2002, January 14). UIC's scholarship of practice. OT Practice, 11-12.

Koenig, K., Johnson, C., Morano, C. K., \& Ducette, J. P. (2003). Development and validation of a professional behavior assessment. Journal of Allied Health, 32(2), 86-91.

LaGrossa, J. (2005, March 7). Opening new doors in Philadelphia. Advance for Occupational Therapy Practitioners, 22-23, 51.

Leonardelli, C. A., \& Caruso, L. A. (1986). Level I fieldwork: Issues and needs. American Journal of Occupational Therapy, 40, 258-264.

McCreedy, P. (1994, Dec. 22). Taking the path less traveled. OT Week, 16-17. 
Moffett Boyd, M. E., \& Garbarini, J. G. (2001, May 21). Helping build healthy communities through OT fieldwork. OT Practice, 17-21.

Moffett Boyd, M. E., \& Garbarini, J. G. (2004, January 5). Creative links: Supporting the community while meeting strategic goals. OT Practice, 11-15.

National Board for Certification in Occupational Therapy, Inc. (2003, Spring). Active certificants by location. Report to the profession, 5.

National Board for Certification in Occupational Therapy, Inc. (2004). A practice analysis study of entry-level occupational therapist registered and certified occupational therapist assistant practice. OTJR: Occupation, Participation and Health, 24, supplement 1.

Platt, N. P., Martell, D. L., \& Clements, P. A. (1977). Level I field placement at a federal correctional institution. American Journal of Occupational Therapy, 31, 385-387.

Rydeen, K., Kautzmann, L., Cowan, M. K., \& Benzing, P. (1995). Three faculty-facilitated, community-based Level I fieldwork programs. American Journal of Occupational Therapy, 49, 112-118.

Scott, S. B. (2000, May 22). Community-based fieldwork opportunities: Level I and Level II experiences. OT Practice, 14-18.

Shalik, L. D. (1990). The Level I fieldwork process. American Journal of Occupational Therapy, 44, 700-707.

Yanoshek, M. C., Fuguet, L., \& Rose, A. (1997). Group models: A creative approach to fieldwork education. In The reference guide to fieldwork education and program development (pp. 68-76). Philadelphia: Philadelphia Region Fieldwork Consortium.

\section{A Must-Have Resource for Every Fieldwork Supervisor!}

\section{The Essential Guide to Occupational Therapy Fieldwork Education}

\section{RESOURCES FOR TODAY'S EDUCATORS AND PRACTITIONERS}

Edited by Donna M. Costa, MS, OTR/L

$\mathrm{F}$ lieldwork education is a vital piece of every occupational therapy student's education. In this comprehensive manual, occupational therapy fieldwork educators in both academic and clinical settings will learn how to prepare a student fieldwork manual for clinical sites and educate staff about the changes in fieldwork education over the past 10 years. Academic fieldwork coordinators, working to put together an effective fieldwork experience, will find resources to share with colleagues and new ideas to utilize.

\section{Order \#1231-J}

\$59 AOTA Members घ \$83 Nonmembers

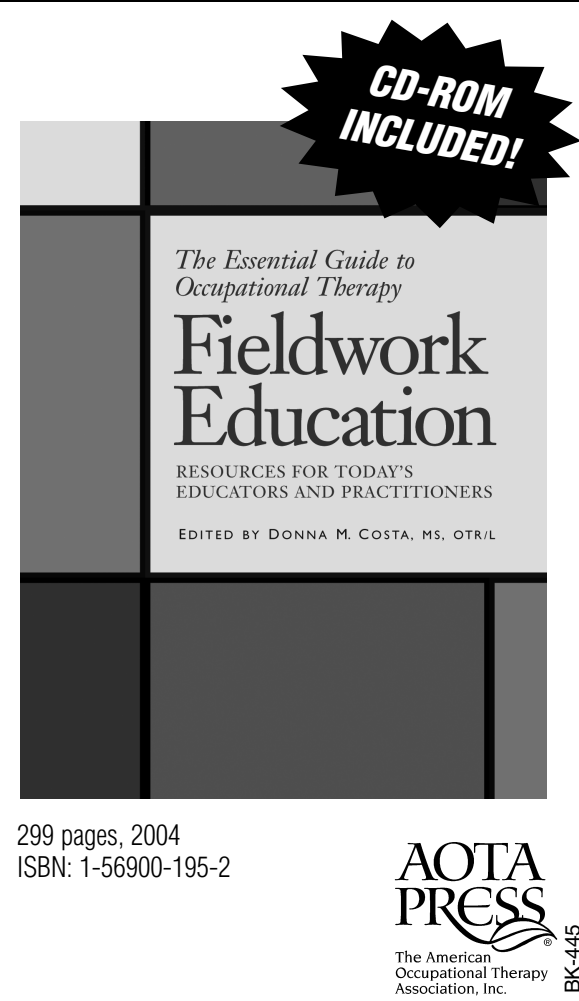

Call: 877-404-AOTA $\square$ Shop: www.aota.org (Books, Products, \& CE) 